UDC: 821.134.2-31.09 Laforet C.

DOl: https://doi.org/10.18485/beoiber.2019.3.1.3

\author{
Luca Cerullo' \\ Università degli Studi di Napoli L'Orientale \\ Italia
}

\title{
LA FIGURA DE LA CRIADA EN LA NARRATIVA DE CARMEN LAFORET: ANÁLISIS DE UNA EVOLUCIÓN
}

\begin{abstract}
Resumen
Se propone un estudio sobre la configuración del personaje de la criada en la novelística de Carmen Laforet. Se analizan tres novelas, Nada, La isla y los demonios y La insolación. A partir de un respaldo metodológico basado en el estudio sobre el personaje literario, se analiza la construcción del personaje de la criada en la autora, subrayando las técnicas de caracterización de las figuras correspondientes, con el fin de detectar las pautas de una evolución estilística y estructural en la autora a la hora de perfilar esta especial categoría de personaje.

Palabras clave: Carmen Laforet, criada, personaje novelesco.

\section{THE FIGURE OF THE MAID IN THE NARRATIVE OF CARMEN LAFORET: ANALYSIS OF AN EVOLUTION}

\section{Summary}

The paper studies the configuration of the maid, a character in Carmen Laforet's novels. Three novels are analysed: Nada, La isla y los demonios and La insolación. Based on a theorical support about the character in narrative, the techniques of the characterization of the corresponding maids will be examined, in order to characterize the guidelines of a structural and stylistic evolution of the writer, so that it will be possible to outline this specific category of character.

Key words: Carmen Laforet, maid, literary character.
\end{abstract}

\section{El personaje novelesco. Un esbozo teórico}

En este artículo analizaré el proceso de construcción del personaje de la criada en tres novelas de Carmen Laforet. Para llevar a cabo esta operación, considero

\footnotetext{
1 lucacerullo84@gmail.com
} 
imprescindible presentar las propuestas hermenéuticas que atañen al personaje novelesco, con el fin de aclarar la cuestión crítica sobre esta especial categoría textual.

El debate teórico en torno al personaje se orienta hacia la redefinición de su importancia en el sistema narrativo, a partir de la superación de las propuestas formalistas y estructuralistas que durante un tiempo considerable han relegado esta categoría a una situación de paridad con otros niveles textuales. En cambio, la complejidad del actor del texto es cada vez más evidente, puesto que su papel no puede considerarse estrictamente destinado al funcionamiento general del relato, tal como se concibe en el Estructuralismo, sino que cabe valorar su grado de mímesis, en virtud de un proceso de identificación que se realiza de forma casi natural desde que un personaje aparece en el texto.

El margen estructuralista y formalista ha generado, entonces, un vacío crítico que las reflexiones hermenéuticas posteriores han colmado solo de forma parcial. Ya Todorov (1976) se quejaba de la escasez de reflexiones esclarecedoras sobre una categoría tan imprescindible del texto narrativo, aludiendo a la complejidad que el personaje conlleva y a la variedad de cuestiones y problemas que lo atañen. Tanto Chatman (1990) como Hamon (1983) intentan compensar esta cortedad de miras, defendiendo la autonomía del personaje, su articulado proceso de configuración y su nivel de identificación o representación de un modelo paradigmático dentro de la sociedad en que se coloca. En especial, Philippe Hamon considera tal proceso de configuración un rasgo exclusivo del personaje, ya que su creación se basa en la alimentación gradual de un perfil a partir de datos que son dados por el narrador. En este caso, es bastante pertinente la idea de Lotman (1973), que ve al personaje como un "vacío semántico", que va llenándose a lo largo de la narración a raíz del conjunto de informaciones que configuran su identidad. Es igual de oportuna la propuesta de Barthes (1970) sobre la existencia y construcción de un código sémico, es decir, un conjunto de motivos, algunos repetidos y otros contrastivos, que alimentan la heterogeneidad del personaje novelesco y determinan su salida de una dimensión puramente funcionalista.

Recientemente, la categoría ha cobrado aún más interés y valor. Una vez reconocida su imprescindibilidad (Marchese 2009) y su rol de eeje principal de la narración" (Delibes 2004: 126), la crítica se ha detenido en el proceso de construcción. En especial, dentro del panorama ibérico, cabe señalar la contribución a dichos estudios de Bobes Naves (1990), quien, haciendo hincapié en la base teórica de corte estructuralista, señala las pautas de configuración a partir de la definición de técnicas de presentación, los signos, que acaban perfilando al personaje. Tales signos, además de fijar algunas características, tanto las dinámicas (que cambian o se anulan a lo largo del relato), como las estáticas (que se mantienen), contribuyen a la definición de un marco referencial que completa el perfil del personaje (Bal 1987). El marco de referencia es objeto de análisis también de la lectura de Alex Woloch (2003), a quien se debe el concepto de “espacio del personaje", una idea que puede considerarse como síntesis de los varios elementos hasta ahora brevemente presentados. Con la noción de "espacio del personaje", Woloch introduce una categoría fija de rasgos definitorios que contempla la referencialidad de la 
que habla Bal, añadiendo el componente de la relación entre varios espacios presentes en el texto, que remiten a los personajes correspondientes. De este modo, se completa la información: cada personaje vive dentro de su espacio, y cada espacio coexiste con el de otro u otros personajes, en virtud de una convivencia que puede ser pacífica, conflictiva, empática o discordante, según los casos.

En el complejo y variado sistema de personajes, existe una diferencia fundamental y lógica entre aquellos que tienen centralidad en el relato -los protagonistas-, y un conjunto de figuras que constituyen los personajes secundarios o periféricos. Este esquema, que se mantiene por lo general en cualquier obra narrativa, no está exento de reflexiones críticas, ya que solo de forma aparente puede presentar cierta linealidad de interpretación.

Ya Bobes Naves (1990) señala cómo este límite se derrumba con la época moderna, ya que la diferencia teorizada por Forster entre personaje redondo multidimensional y central-, y plano -unidimensional y periférico-, aparece irremediablemente caducada. La revolución narrativa ocurrida en torno al personaje a comienzos del siglo $\mathrm{XX}$ demuestra que estas categorías solo pueden servir de brújula para orientarse en el sistema general, pero su misión orientadora se concluye a la hora de profundizar el análisis.

Si por un lado aceptamos la fisiológica centralidad del protagonista, no podemos negar que el personaje secundario, en especial algunos modelos de personajes menores, es imprescindible para el desarrollo del relato. Además, como bien señala Weinrich (1964), el personaje secundario, aunque no tiene centralidad en la narración, puede adquirir importancia desde el punto de vista del contexto histórico-social, con el que establece una relación de identificación o de conflictividad y rebeldía (Weinrich 1964). Asimismo, Bobes Naves (1990) señala el proceso de identificación que tiene el personaje secundario con el trasfondo histórico y también la capacidad de presentar otro punto de vista, tanto adherente como en oposición al relato central.

Ahora bien, la figura de la criada representa uno de los actores más presentes en la narrativa, pero más en general en la literatura española. A partir de las sirvientas celestinescas, Areúsa y Lucrecia, el personaje de la criada menudea en la producción literaria elaborada en España desde los albores de la modernidad hasta nuestros días. Las dos mujeres ancilares de La Celestina bien cumplen su papel secundario, pero fundamental, en la primera obra moderna de la literatura española. A partir de entonces, la criada se reafirma en la literatura nacional arropada de esa extraña centralidad que le confiere su imprescindibilidad para el funcionamiento general del relato. De hecho, con respecto a otros personajes secundarios, la sirvienta o las sirvientas son irrenunciables para que cada pieza del engranaje narrativo arranque, se desarrolle y llegue a un final lógicamente aceptable. El factor desencadenante es, sin duda, el grado de intimidad que se establece entre sirvienta (son sobre todo mujeres, aunque no faltan casos de criados) y señor o señora, lo que permite que un personaje ajeno al relato principal tenga acceso 
directo al universo, tanto físico como ideal, del protagonista. Desde su particular punto de vista, que corresponde paradigmáticamente a su entorno social, la criada observa, analiza y finalmente, aunque no siempre, pone en tela de juicio las actitudes de sus dueños; una operación silenciosa que desde el punto de vista estructural ayuda a conferir multidimensionalidad a los personajes. Gracias a la mirada de la criada, el lector puede percatarse de otra faceta del protagonista, o bien puede asistir a la misma historia, pero contada de otra forma o desde un ángulo diferente. De esta forma, la criada no solo completa el cuadro de personajes, sino que amplía el "espacio" del protagonista, hasta otorgar y acentuar su verosimilitud.

El procedimiento narrativo recién descrito apela a dos conceptos fundamentales, ya mencionados: la referencialidad del personaje (Bal) y el factor del "espacio del personaje" (Woloch). Por un lado, el concepto de referencialidad aspira a perfilar el ámbito de referencia de cada personaje, es decir, costumbres, entorno social, evocaciones de su pasado, etcétera. Por otro, gracias a la delimitación del espacio del personaje, se define también el límite, verosímil, de los movimientos de cada actor textual. Poco a poco, el autor va definiendo el espacio del personaje, y esta configuración permite desvelar el sistema de referencialidad del que se vale.

\section{Las criadas en la narrativa de Carmen Laforet}

La figura de la criada constituye un personaje de notable importancia también en la novelística de Carmen Laforet. Más allá de las semblanzas autobiográficas apreciadas en esa translación a la página de personas realmente presentes en la vida de la autora, podría decirse que Laforet se vale de esa figura para implementar la multidimensionalidad de su sistema de personajes. De hecho, la criada, junto a otros modelos como la madrastra, la abuela o el artista, representa un prototipo que aparece en cada novela de Laforet y que, a lo largo de las diversas publicaciones, se enriquece de detalles, de información $y$, por tanto, de complejidad novelesca. Este procedimiento atañe, por lo general, a cada prototipo social presente en la narrativa de la autora.

Para Illanes Adaro (1974), la criada en la novelística de Laforet ejerce la función de alimentar el realismo a través de un proceso de identificación con el momento histórico que vive $y$, en segundo lugar, reconstruye el mundo arcaico del que procede. De hecho, sobre todo en lo que concierne a Antonia, la criada de Nada (1945), la realidad histórica que vive la sociedad española en la posguerra está bien representada a través de esta mujer que se presenta como una "máscara del dolor". Un dolor que, por extensión, afecta a todo el país. Asimismo, Vicenta, la sirvienta de La isla y los demonios (1952), es un espejo perfecto del conjunto de tradiciones y supersticiones del mundo canario, presentado en la novela en su dimensión más ancestral. La reflexión de Illanes Adaro encuentra su respaldo en lo que asevera Bobes Naves sobre el personaje secundario (1990), confirmando la representación del trasfondo histórico, algo que el personaje 
central, por lo general, realiza solo de forma parcial. Bobes Naves añade también el elemento del punto de vista; en este caso, la criada ofrece una perspectiva diferente a la que asimila la voz narradora o el mismo protagonista. Esta idea se confirma también a través del proceso de caracterización; dentro una división que quizás resulte demasiado rígida, entre una descripción limitada al aspecto, que llamaremos Prosopografía, y otra más amplia y detallada que contempla también la dimensión interna, psicológica y moral, definida como Etopeya, el personaje de la criada se coloca casi siempre en la primera, sin desarrollar su perfil interior y limitándose a una descripción meramente exterior. Lo cierto es que coexisten otros elementos de caracterización, que superan este cuadro aproximativo: la relación entre personaje y objeto, la relación con el espacio y el entorno (Álamo Felices 2006), por ejemplo, son solo algunos de los factores que dificultan la división antes citada. Además, esta partición parece bastante desdibujada en Laforet, puesto que, como veremos, se asiste a un camino de evolución que determina la salida gradual de la criada de una dimensión puramente exterior hacia un universo más propio de los protagonistas, incluyendo algunos elementos claves de caracterización inherentes a su personalidad, su mundo interior, su espacio de acción.

Para aplicar estas ideas a la figura de la criada en Laforet, nada mejor que recurrir al orden cronológico de cada obra: Nada se publica en 1945, La isla y los demonios en 1952 y La insolación, en 1963. La distancia temporal entre las tres obras -quedando fuera La mujer nueva (1955) y la novelística breve de los años cincuenta-, representa el primer indicio de una maduración que caracteriza la narrativa de la autora. Aunque su primera novela fue la más célebre y exitosa, no faltan críticos que, a lo largo de su trayectoria, señalan un evidente proceso de evolución. A partir de las lecturas de Entrambasguas (1952) y Marra López (1963), casi contemporáneas a las publicaciones de los libros, hasta llegar a estudios más recientes (Quintana Tejera 1997; Quevedo 2012), novelas que en principio quedaron al margen o por lo menos fueron reseñadas a partir de una impropia comparación con la primera, han sido y siguen siendo objeto de una profunda revalorización crítica.

En esta línea de maduración, es importante señalar también una sofisticación en cuanto a la caracterización del personaje. En el caso de la criada, Carmen Laforet recorre una trayectoria evidente de ampliación, un término que aquí está sacado directamente del concepto procedente de Woloch, presentado en el apartado preliminar. Las tres novelas aquí analizadas presentan, de hecho, a tres criadas distintas; cada una de ellas supera a la anterior y amplía el espacio particular de representación.

De esa manera, entre Antonia, la criada de Nada, y Frufrú, sirvienta de La insolación, hay diferencias que legitiman un proceso de evolución en términos de configuración del personaje novelesco propio de la escritora.

Me gustaría señalar las pautas de este proceso de caracterización, recurriendo a ejemplos textuales que atestiguan un camino progresivo tangible en los personajes de Antonia, Vicenta y Frufrú. 
Como es sabido, Nada cuenta la historia de Andrea, una joven que, tras viajar a Barcelona para estudiar, habiendo proyectado en la ciudad todo un conjunto de ilusiones y expectativas, queda irremediablemente desencantada y decide marcharse antes de tiempo. Su estancia en Barcelona será caracterizada por la asfixiante monotonía y la locura del piso en el que se aloja, ocupado por parientes delirantes, y por la amistad con Ena, su verdadero salvoconducto para salir de la ciudad.

Antonia es uno de los primeros personajes en aparecer en Nada. Su descripción se basa sobre todo en su aspecto físico. Andrea se da cuenta de su presencia casi enseguida después de pisar el umbral de la casa:

Al levantar los ojos vi que habían aparecido varias mujeres fantasmales. Casi sentí erizarse mi piel al vislumbrar a una de ellas, vestida de traje negro que tenía trazas de camisón de dormir. Todo en aquella mujer parecía horrible y desastrado, hasta la verdosa dentadura que me sonreía. La seguía un perro, que bostezaba ruidosamente, negro también el animal, como una prolongación de su luto. Luego me dijeron que era la criada, pero nunca otra criatura me ha producido impresión más desagradable (Laforet 1999: 16).

El fragmento confirma que el personaje se coloca en un escalón inferior al de los demás ocupantes de la casa. De hecho, esta perifericidad se mantendrá en toda la novela, quedando la mujer totalmente al margen de los acontecimientos producidos en la familia. No es casual que el análisis de Salvador Crespo Matellán (1988), una de las primeras aproximaciones estrictamente centradas en los personajes de Nada, deje fuera a la criada. El aspecto de monstruo y el luto que la caracterizan, se confirmarán elementos reiterados para el proceso de configuración; componentes a los que hay que añadir el hecho de que la mujer apenas habla. El silencio de Antonia, signo de definición de este personaje, oculta su posible odio a la familia a la que sirve, evidente en su mirada severa e intolerante hacia las costumbres, las frases y la forma de vivir de sus señores. La presencia del perro, además, contribuye a empequeñecer su papel en la casa en aras de una relegación permanente a un estadio marginal dentro del sistema de personajes.

Su espacio, entonces, parece bastante reducido. La referencia al negro, color único y dominante de su vestimenta, evoca un luto que la mujer ha sufrido en una época anterior, una pérdida que puede remitir a la guerra civil o a otras circunstancias, pero que ha determinado su soledad y su necesidad de ampararse en la casa de la calle Aribau. Sin embargo, esta dimensión nunca se explora; Antonia llevará prendas negras, pero nunca se mencionará a quién perdió y en qué circunstancias, lo que constituye un elemento fundamental para establecer su perifericidad respecto a otros personajes, más centrales en la narración.

Si, como señalaba Bobes Naves (1990), los personajes secundarios tienen el privilegio de poder salir y entrar en la narración sin ninguna lógica, podemos afirmar que Antonia cumple con dicho requisito, ya que al final de la novela, después del suicidio del tío de Andrea, Román, la sirvienta abandona la casa sin dar ninguna explicación, como 
bien señala el personaje de Gloria: “-Antonia se marchó esta mañana con Trueno. [...] Se marchó esta mañana de madrugada, mientras que Juan dormía. Es que Juan no quería dejarle llevarse al perro. $Y$ ya sabes tú que Trueno era su único amor... Se han fugado los dos juntitos." (Laforet 1999: 263).

Otro elemento dominante en Nada es la animalización que afecta a casi todos los personajes. Angustias, por ejemplo, establece cierta asociación directa con un ave, al vestir casi siempre "un fieltro marrón adornado por una pluma de gallo, que daba a su dura fisionomía un aire guerrero" (Laforet 1999: 32), mientras que Román en muchas ocasiones parece una fiera, y su buhardilla, un cubil. Antonia, desde la primera escena, aparece acompañada de un perro, Trueno, que la sigue en todo lo que hace. El perro es, podríamos concluir, su única y fiel compañía. Esta animalización se hace más que evidente en algunos pasajes: por ejemplo, cuando los aullidos que Andrea oye al volver a casa parecen proceder del animal y, en cambio, son de la propia mujer.

Jamás había oído gritar de aquella manera en la casa de la calle de Aribau. Era una chillido lúgubre, de animal enloquecido, el que me hizo sentarme en la cama y luego saltar de ella temblando. Encontré a la criada, Antonia, tirada en el suelo del recibidor, con las piernas abiertas en una pataleta trágica, enseñando sus negruras interiores, y con las manos engarabitadas sobre los ladrillos (Laforet 1999: 256)

Más allá de su aspecto monstruoso y de su especial relación con el perro, poco se cuenta de la criada. Su espacio queda, de hecho, bastante restringido a la categoría de personaje secundario. Ni se cuenta su pasado, ni se indaga su dimensión psicológica, quedando su historia particular envuelta en el misterio, en especial en relación con el luto. Este dato me parece de notable importancia ya que será uno de los elementos que, en cambio, sí será aclarado en la novela posterior, La isla y los demonios, donde aparece la criada Vicenta.

La estructura diferente a la novela anterior de La isla y los demonios, con una voz narradora en tercera persona, permite un desarrollo distinto a Nada; a partir de una diferente focalización, las historias paralelas pueden adquirir cierta centralidad en el relato. Tal como ha señalado Hugo Carrasco (1982), coexisten en la novela varias historias particulares, o en algunos casos concurrentes, que contribuyen a una visión más completa de la historia. Por ejemplo, no son pocas las escenas en que el mismo acontecimiento o detalle está narrado desde puntos de vista y ángulos distintos. Un ángulo de la narración que, como se verá, también incluye a Vicenta, la majorera.

El argumento de la novela gira en torno a Marta Camino, una chica algunos años más joven que Andrea, y de su salida de la adolescencia. La llegada de algunos invitados a la isla de Gran Canaria, donde ella vive, se recibe como un "antes y después" de su vida, ya que después de conocer al pintor Pablo, Marta decide que su vida tiene que emprender otro rumbo. Su salida no será para nada fácil: una familia hostil, en especial su hermano José que le hace de padrastro, y la histérica Pino, su mujer, dificultarán 
enormemente el viaje de Marta, quien, al final $y$ tras numerosos periplos, logra abandonar la isla.

La sirvienta de La isla y los demonios ha despertado ya el interés de la crítica: si Joaquín de Entrambasaguas ya señalaba su creación como uno de los mayores logros de la novela (1952), José Luis Cano y Antonio de Hoyos no dejan de destacar el matiz trágico del personaje y la verosimilitud de su perfil. Por su parte, la misma escritora consideraba su historia "un cuento dentro de la narración" (Laforet y Fortún 2017: 107), admitiendo el valor literario de Vicenta y del capítulo dedicado a ella.

Este personaje mantiene una relación profunda con su tierra, Gran Canaria, puesto que la dimensión ancestral y supersticiosa de la isla representa, de hecho, su hábitat. Ahí la criada se educó y creció, asimilando las creencias y la cosmovisión de los isleños. De hecho, se presenta depositaria de la cultura arcaica canaria y por eso se erige en paradigma de un pueblo entero, cumpliendo de forma plena el papel de representación de un sujeto colectivo. "Aquel domingo por la tarde, Vicenta, la majorera, cambió su faldamenta, color canela por un traje negro, se puso un pañuelo nuevo en la cabeza y se cubrió los hombros con una toquilla de lana negra y grandes flecos" (Laforet 1991: 93).

Como puede verse, vuelve a aparecer el negro como color de caracterización. Tal como ocurría con Antonia, Vicenta se describe sobre todo a través de su vestimenta, pero esta dimensión se superará en el capítulo XVI, donde Vicenta aparece como protagonista real. Al contrario de Antonia, de quien se subraya su aspecto monstruoso, Vicenta parece haber conservado su belleza y su fuerza. Se describe de hecho como una mujer que, a pesar de su "cara acartonada", "los años no podían con ella. Era más fuerte entonces que de muchacha" (Laforet 1991: 273).

Tras la salida presentada en el capítulo VI, el personaje vuelve a la sombra, pero luego reaparece con la centralidad propia de un protagonista, en el capítulo XVI, a raíz de una técnica narrativa que Laforet aplica también a otros personaje secundarios de la novela.

El capítulo, que consta de unas diez páginas, se centra en la historia particular de la majorera. Se cuenta su pasado en Fuerteventura, isla de la que debió escapar tras la muerte de sus propios hijos. Además, se dan detalles sobre su especial relación con Teresa, su señora y madre de Marta y José, ya que esta "se confiaba a ella. Se inclinaba a su vida con interés real, ansioso" (Laforet 1991: 244). Teresa fue la única en aceptar a esa mujer que lo había perdido todo, de la que en Fuerteventura habían empezado a circular voces sobre su brujería y su capacidad de lanzar mal de ojo a los isleños. Tras la amenaza de su hija más joven, que le confiesa que tendrá que abandonar la isla si no quiere que el marido de la joven huya con el hijo, Vicenta deja para siempre su lugar de origen para llegar a la isla más próxima:

Había dejado la casa abierta, y abandonadas las cabras y las gallinas. Abandonado el arcón con los trajes y el costurero con las labores, y el retrato de la boda... El cura le arregló los papeles de sus ventas, y en ellos lo incluyó todo. Cogió una bolsita con dinero que se colgó al cuello, y sin volver la cabeza atrás, fue a Puerto de Cabras. 
Luego embarcó. Unos meses más tarde, en la Gran Canaria, encontró a Teresa. (Laforet 1991: 254)

El capítulo ofrece, además, detalles sobre su aspecto y su costumbre. Vicenta es una mujer de cierta belleza, tanto que "sus pechos altos le henchían las blusas y se llevaban las miradas de los hombres..." (Laforet 1991: 244), que ha adquirido el vicio de fumar y que tiene una idea muy clara sobre la relación entre criada y dueño: "Orgullosos todos los señoritos nuevos, que tratan bien a las criadas, que no las riñen ni se meten en sus vidas, pero pasan los ojos sobre ellas como si fueran leños" (Laforet 1991: 24). Es decir, su espacio se amplía hasta concederle un papel de evidente centralidad en el relato, confirmando la idea de que, aunque nominalmente secundario, el personaje de la criada es imprescindible para la narración. Al contrario de Antonia, sí se conoce el porqué del luto, la muerte de casi todos sus hijos, como también se da explicación del especial afecto por Teresa, siendo esta la única responsable de su nuevo comienzo en Gran Canaria. Como señala Luis Quintana Tejera, este personaje destaca, entre otras cosas, por "su apego al pasado y su fidelidad a la casa de los Camino que se deposita exclusivamente en la figura de Teresa" (Quintana Tejera 1997: 184). Estos detalles contribuyen a la multidimensionalidad del personaje, que abandona definitivamente el estatus de secundario y unidimensional. Otro elemento que también influye en este proceso es el punto de vista: Vicenta desarrolla un punto de vista propio. Es un aspecto importante a la hora de valorar su peso en la novela: su mirada se centra sobre todo en la joven Marta, que para la criada es nada más que una imagen deformada de su madre y para nada heredera de su personalidad: "Era la hija de Teresa. Sin la gracia ni la belleza de Teresa, y rubia como su padre, pero era hija suya. Una niña esbelta, de cejas rectas y manos tostadas. [...] La había visto nacer, y había tenido, en tiempos muy lejanos, unos oscuros celos de la niña, por ser hija de quien era" (Laforet 1991: 104).

Como se ha visto, aunque manteniéndose entre las filas de personajes secundarios, a las que la criada debe pertenecer por definición, Vicenta da señas de una personalidad compleja y multidimensional, lo que confirma que, con respecto a la criada de Nada, Carmen Laforet ha alcanzado una dimensión más madura de caracterización, perfilando a un personaje de perfecta configuración e intensidad dramática. Eso no impide, desde luego, que entre las dos señoras haya analogías, puesto que, como también ha advertido Quintana Tejera ambas "viven la necesidad de gritar los secretos que ambas casas quisieron ignorar, denunciar a quienes, en el nivel de los sentimientos, fueron culpables de lo sucedido" (Quintana Tejera 1997: 187). Por último, ambas tienen un favorito en la casa: Román para Antonia y Teresa para Vicenta, y tanto la primera como la segunda desaparecen de la narración de manera autónoma, pero el nivel de caracterización marca la profunda diferencia entre una y otra. Si Antonia permanece en el telón de fondo de Nada, no puede afirmarse lo mismo para Vicenta, siendo su espacio y su marco referencial mucho más amplio y detallado. 
Este excursus se completa con Frufrú, la criada de la familia Corsi en La insolación. Francisco García Quevedo la define "un personaje femenino con un nombre tan estrafalario [...] antigua compañera de circo del padre de Anita y Carlos, convertida en su cuidadora ante las largas ausencias del progenitor de ambos. Frufrú representa ante todo la diferencia, el contraste con una sociedad pacata y constreñida como es la española de Posguerra" (Quevedo 2008: 150), mientras que para Galdona Pérez estamos ante "un ejemplo magnífico de la independencia" (Galdona Pérez 2001: 47). Se trata de un personaje que se presenta distinto tanto a Antonia como a Vicenta. De hecho, sus orígenes no parecen tan humildes, y creo importante el hecho de que, mientras tanto, el papel de la criada se haya profesionalizado desde el punto de vista institucional en España. La criada de La insolación aparece como institutriz de los chicos de la casa, Anita y Carlos Corsi, más que como sirvienta.

La novela, que constituye la primera pieza de una trilogía, "Tres pasos fuera del tiempo", que nunca llegó a su fin, cuenta tres veranos del joven Martín Soto en Beniteca, un pueblo costero de la costa levantina. Anita y Carlos Corsi, dos hermanos, serán sus amigos fieles y acompañantes de aventuras, enfrentamientos y descubrimientos típicos de la adolescencia. En esta novela también, la familia del protagonista representa un obstáculo para su libertad. De hecho, su padre Eugenio no tolera la amistad con los Corsi ni la manera de su hijo de matar el tiempo. Por su cuenta, la madrastra del muchacho manifiesta un verdadero odio a Martín, y hace todo lo posible para que Eugenio lo aleje definitivamente de Beniteca. De todas formas, el relato central es el camino adolescente de Martín, compartido con los estrafalarios Corsi, una relación que se mantendrá también en la segunda novela de la trilogía, Al volver la esquina.

Desde el comienzo de la novela, Frufrú aparece envuelta en un enigma. Martín Soto, el protagonista, se pregunta qué rol tiene en la familia Corsi. Desde el punto de vista de la configuración del personaje, ese dato, aparentemente de escasa importancia, cobra un valor determinante. De hecho, ni Antonia ni Vicenta gozan del privilegio de ser anunciadas por el narrador, sino que irrumpen en el relato. Frufrú, al contrario, es precedida por una suerte de expectación que empieza a perfilar el enigma que la afecta.

Por la tarde conoció a Frufrú. Frufrú dormitaba con la cabeza apoyada en el respaldo de un banco balancín colocado junto a la explanada que se abría frente a la casa de los Corsi. El balancín tenía toldo, pero estaba protegido además por la sombra de un pino. Frufrú debía estar cosiendo cuando el sueño la sorprendió. La labor le había resbalado al suelo y llevaba puestas las grandes gafas de carey que usaba para coser y que le comían media cara.

Martín, entre Carlos y Anita, la estuvo contemplando fascinado. Todo se podía esperar de los Corsi. Hasta una mamá así. Martín nunca había visto una señora parecida. Era pequeñita y con la piel reseca y arrugada. El pelo teñido de rubio azafrán sobre una carita de mono retocada con varias capas de pintura. La blusa, de un amarillo brillante, era sin mangas y con un gran escote, y en el escote collares de colorines, y junto a las muñecas, al final de los bracitos resecos, pulseras baratas de 
colorines también. Llevaba falda acompañada con lunares negros sobre fondo rosa, piernas sin medias y pies calzados con zapatos azules de tacón alto. (Laforet 1985: 50)

Nótese la insistencia en la variedad cromática de la vestimenta de la criada. Destaca por ser, con respecto a Antonia y Vicenta, una mujer que prefiere el color al negro del luto. Este dato conlleva un gusto distinto que también puede considerase una señal de otra pertenencia social. De hecho, la sirvienta de los Corsi no pertenece para nada al mundo pobre de las criadas de las novelas anteriores, sino que forma parte de otro escalón social, más cómodo y culto.

A lo largo de la novela, el narrador insiste en "lo que viste» Frufrú, alimentando de este modo la caracterización extraña de la sirvienta.

Fue en aquel momento cuando Martín se dio cuenta de algo perteneciente a Frufrú que no había acabado de captar el año anterior. Los vestidos de Frufrú, esos vestidos de tela brillante que ya no sorprendían a Martín sino que incluso le gustaban, pues no concebía a Frufrú sin ellos, tenían a pesar de su brillo un aire ajado, como si hubieran sido usado en la guardarropía de un teatro. El cabello de Frufrú había cambiado de tono desde la última vez, tenía una calidad de estopa y ahora descaradamente amarillo. Los largos pendientes en tono granate, la blusa verde y la falda estampada en rabos multicolores y alas conocía Martín. Las manitas de Frufrú con las muñecas adornadas por todas aquellas pulseras tan conocidas, eran carnosas, estropeadas y con las uñas desgastadas por el trabajo. (Laforet 1985: 78-79)

Es decir, Frufrú escapa de cualquier encasillamiento social. Si por un lado aparece como una mujer que cuida mucho de sí misma y de su aspecto, hasta parecer en algunos casos frívola, por otro presenta pequeños detalles que desvelan su trabajo cotidiano, que conlleva esfuerzo físico y desgaste del cuerpo. De todas formas, la reiterada referencia al aspecto, este también excéntrico, será un enigma sin resolver. La mujer, pues, no se identifica con ningún modelo social de la época.

De forma opuesta a sus colegas de las otras novelas, Frufú participa en la acción central, ya que en varias ocasiones se encuentra en la posición de cómplice de las andanzas de los tres muchachos. Además, los chicos la interpelan, le piden que cuente su fascinante historia, a caballo entre verdad y fantasía. Como asevera Mark Del Mastro: "Frufrú even partcipates in the teenager's mischievous actitivities when, for example, she joins Carlos and Martín on an evening jaunt of drinking and dancing in downtown Beniteca, an inappropriate activity for a guardian, especially an older, unmarried woman in 1940s Spain" (Del Mastro 2004: 47). Su personalidad, al contrario de lo que ocurría con Antonia y Vicenta, no parece sujeta a un proceso de represión. Frufrú es una mujer que valora la independencia y sobre todo reluce su faceta más militante al tratar temas como la independencia femenina: 
Tú, quieto. Ve con Martín por ahí, hijo. La niña me pidió que no la molestarais. Os lo he dicho, las mujeres necesitamos libertad. Ah, sí. Necesitamos que nos dejen libres como el aire. Una mujer encerrada es una mujer dañina. [...]

Eso es otra cosa. Pero si yo quiero ir al pueblo voy al pueblo y si quiero un día coger la maleta y marcharme, pues, me voy. Corsi lo sabe. Por eso estoy con los niños, porque quiero. Si un día me canso de España me presento en el consulado y me voy. Ah, sí. Por eso me quedo, porque puedo irme... Y si quiero ir al pueblo aunque me tiren piedras, voy al pueblo. Pero no quiero ir al pueblo. $Y$ si quiero ir a misa, me disfrazo con unas medias y me pongo una capa para taparme los brazos como hay que hacer en este pueblo y me pongo el velo de viuda de Carmen, y voy... Pero no quiero ir a misa vestida de carnaval, pues no voy. Ya lo sabes, niño. (Laforet 1985: 94-95).

Si, aunque distintas desde el punto de vista de la caracterización, Antonia y Vicenta establecían ciertas analogías (Quintana Tejera 1997), con Frufrú asistimos al nacimiento de un personaje tan distinto y aislado que su ubicación dentro del sistema de personajes es notablemente difícil. Guapa, culta, libre, Frufrú no es nada más que el producto final de un camino de evolución propio de la autora, que decide alejar a este tipo de criada del modelo tradicional y otorgarle otros elementos de caracterización. De esta manera, Frufrú se presenta como espejo de una sociedad que rehúye la clasificación y el encasillamiento, optando por una libre elección del destino, tan rara en la época en que se desarrolla la narrativa de Carmen Laforet.

\section{Conclusiones}

El análisis recién expuesto demuestra una evolución de Carmen Laforet a la hora de perfilar a sus personajes secundarios. La especial categoría de la criada, por ejemplo, se coloca en el centro de dicha maduración estilístico-estructural. Con respecto a la multidimensionalidad del personaje, elemento de determinación entre un papel central y secundario, hemos visto cómo solo el personaje de Antonia, la criada de la opera prima de la autora, Nada, se queda en la dimensión de la Prosopografía, es decir, de una mera descripción exterior, en el texto orientada a definir su aspecto de mujer/monstruo. Este tipo de relegación no permite ampliar el espacio del personaje de la sirvienta. Al contrario, lo relega a una perifericidad confirmada también por la identificación que la mujer tiene con el perro Trueno, y no con los ocupantes de la casa de la calle Aribau, y por el hecho de que la mujer habla en muy pocas ocasiones, quedando su mirada como único recurso para comunicarse con los demás.

La caracterización de Vicenta, criada en La isla y los demonios, busca perfilar un personaje completo, perfectamente insertable en el ámbito de una multidimensionalidad. Se cumple, de hecho, una ampliación de su espacio y también de su referencialidad. Gracias también a la estructura de la novela, que se compone de una pluralidad y una concurrencia de historias particulares (Carrasco 1982), el 
personaje adquiere una complejidad distinta, mucho más semejante a la de un posible protagonista. De hecho, algunos capítulos cambian de protagonista: en el caso de Vicenta, el capítulo XVI le confiere ese grado de centralidad que le permite salir, de forma definitiva, de la unidimensionalidad. Su historia particular, algunos detalles sobre costumbres y vicios, y su punto de vista sobre el asunto central, contribuyen a configurar el personaje de forma completa.

Finalmente, el caso de Frufrú, criada en La insolación, se presenta aún más cargado de detalles. Ella aparece como una mujer de una cultura mucho más elevada que sus anteriores colegas, teniendo un periplo vital distinto y más rico de experiencias. Además, esa criada parece haber abandonado la experiencia del dolor que, en cambio, marcaba por completo a Antonia y a Vicenta. Este personaje, al no vivir el mismo luto que sus colegas, se presenta libre de un pasado doloroso, lo que sí puede representar otro factor determinante de diferencia. Frufrú ha elegido la casa en la que servir con total libertad, y posee una visión del mundo, sobre todo del universo femenino, que resulta auténtica, es decir, que no encaja en ningún modelo social presente en la España de la posguerra. Es, en el fondo, un personaje complejo, multidimensional y hasta enigmático, lo que confirma que, en una línea imaginaria que contemple las tres novelas, existe un camino de evolución en la configuración de este personaje periférico pero que, como hemos visto, también es imprescindible para el desarrollo de la narración.

\section{BIBLIOGRAFÍA}

Álamo Felices, Francisco. "La caracterización del personaje novelesco: perspectivas narratológicas". Signa, 15 (2006): 189-213. Impreso.

Barthes, Roland. S/Z. Buenos Aires: Siglo XX, 1980. Impreso.

Bobes Naves, María del Carmen. "El personaje novelesco: cómo es, cómo se construye". Marina Mayoral (ed.), El personaje novelesco, Madrid: Cátedra, 1990. 43-68. Impreso.

—. La novela. Madrid: Síntesis, 1993. Impreso.

Carrasco, Hugo. "Las narraciones concurrentes en La isla y los demonios". Estudios Filológicos, 17 (1982): 23-38. Impreso.

Chatman, Seymour. Historia y discurso. La estructura narrativa en la novela y en el cine. Madrid: Taurus, 1990. Impreso.

Crespo Matellán, Salvador. "Aproximación al concepto de personaje novelesco. Los personajes en Nada de Carmen Laforet". Anuario de Estudios Filológicos, Universidad de Extremadura, XI (1988): 133-147. Impreso.

Del Mastro, Mark. “ldentity achievement and lost innocence in Carmen Laforet's $L a$ insolación. Ojáncano, 25 (abril 2004): 43-60. Impreso. 
Delibes, Miguel. España 1936-1950. Muerte y resurrección de la novela. Barcelona: Destino, 2004. Impreso.

Entrambasaguas, Joaquín de. "La segunda novela de Carmen Laforet". Revista de Literatura, I (1952): 236. Impreso.

Hamon, Philippe. Le personnel du roman. Genève: Librairie Droz, 1983. Imprimé.

Galdona Pérez, Rosa Isabel. Discurso femenino en la novela española de posguerra. Carmen Laforet, Ana María Matute y Elena Quiroga. La Laguna, Santa Cruz de Tenerife: Servicio de Publicaciones, Universidad de La Laguna, 2001. Impreso.

Illanes Adaro, Graciela. La novelistica de Carmen Laforet. Madrid: Gredos, 1974. Impreso. Laforet, Carmen. La insolación. Barcelona: Plaza \& Janès, 1985. Impreso.

—. La isla y los demonios. Barcelona: Destino, 1991. Impreso.

-. Nada. Barcelona: Destino, 1999. Impreso.

Laforet, Carmen, y Elena Fortún. De corazón y alma. (1947-1952). Madrid: Fundación Banco Santander, 2017. Impreso.

Lotman, Yuri. Estructura del texto artístico. Madrid: Istmo, 1973. Impreso.

Marchese, Angelo. L'officina del racconto. Milán: Mondadori, 2009. Stampato.

Marra López, José R. "Carmen Laforet. Novelista perdida y reencontrada". Ínsula, 203 (octubre 1963): 4. Impreso.

Quevedo, Francisco José. "La insolación. Una novela de iniciación”. El Guiniguada, 17 (2008): 141-155. Impreso.

—. Regreso a la isla y los demonios de Carmen Laforet. Valencia: Aduana Vieja, 2012. Impreso.

Todorov, Tzvetan. Teoría de los formalistas rusos. Buenos Aires: Siglo XXI, 1976. Impreso.

Woloch, Alex. The one vs the many. Minor Characters and the Space of the Protagonist in the Novel. Princeton, N.J.; Oxford: Princeton University Press, 2003. Print. 